
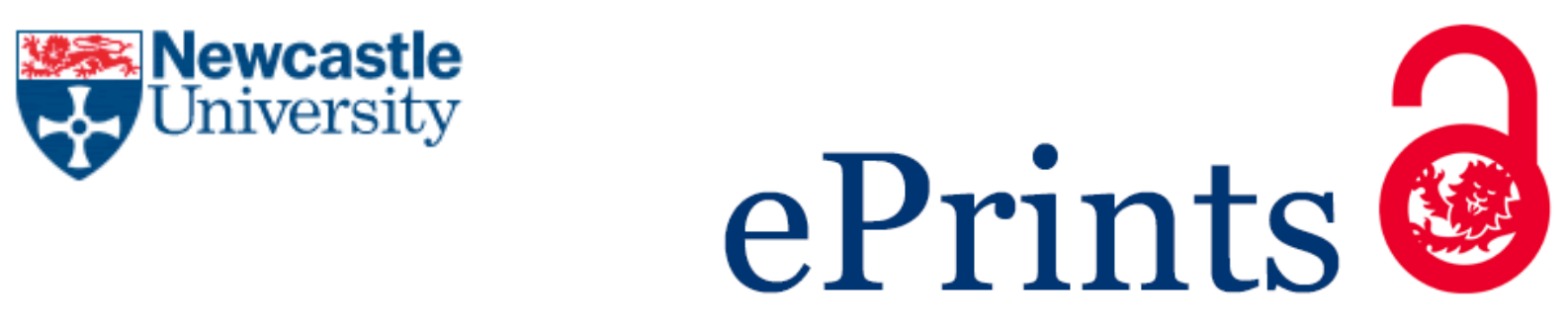

Stewart M, Keightley A, Maguire A, Chadwick B, Vale L, Homer T, Douglas G, Deery C, Marshman Z, Ryan V, Innes N. Investigating the management of carious primary teeth in general dental practice: an overview of the development and conduct of the Fiction Trial. Primary Dental Journal 2015, $4(4), 67-73$.

Copyright:

(C) 2015 Faculty of General Dental Practice.

DOI link to article:

http://dx.doi.org/10.1308/205016815816682146

Date deposited:

$03 / 12 / 2015$

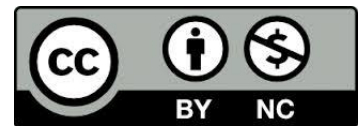

This work is licensed under a Creative Commons Attribution-NonCommercial 3.0 Unported License 


\title{
Investigating the management of carious primary teeth in general dental practice: an overview of the development and conduct of the FiCTION trial
}

\author{
Abstract \\ Management of carious primary teeth is challenging for patients, parents and \\ clinicians. Most evidence supporting different management strategies \\ originates from a specialist setting and therefore its generalisability to the \\ primary care setting is questionable. The UK National Institute for Health \\ Research (NIHR) Health Technology Assessment (HTA) has commissioned \\ the FiCTION trial; a multi-centre primary dental care randomised controlled \\ trial $(\mathrm{RCT})$ to determine the most clinical and cost effective approach to \\ managing caries in the primary dentition in the UK. This large trial began in \\ 2012, is due to be complete in late 2017 and involves 72 practices and 1124 \\ children initially aged 3-7 years with dentine caries. Following randomisation \\ to one of three caries management strategies. Clinical, radiographic, quality of \\ life, treatment acceptability and health economics data are collected during \\ the three-year follow up period. This article provides an overview of the \\ development and conduct of FiCTION and discusses some approaches \\ adopted to manage challenges and achieve the patient recruitment target.
}


Investigating the management of carious primary teeth in general dental practice: an overview of the development and conduct of the FiCTION trial

\section{Introduction}

The FiCTION (Filling Children's Teeth: Indicated Or Not?) Trial is a Randomised Controlled Trial (RCT) based in primary dental care, comparing alternative methods of managing caries in the primary dentition. This article describes some of the challenges encountered on the way to recruiting the target number of participants needed, and how the FiCTION research team has worked along with the FiCTION practice teams to overcome those challenges.

Dental care for the vast majority of children in the UK is provided by general practitioners rather than specialists; a situation common to many other countries. However, much of the evidence for the efficacy of restorations in the primary dentition is based on treatment undertaken in secondary care by specialists. ${ }^{1-4}$ This has contributed to the uncertainty surrounding the most appropriate approach to managing carious primary teeth, with dental undergraduate teaching historically based on guidance advising that carious primary teeth should be managed by complete removal of carious tissues followed by placement of a restoration. ${ }^{5}$ More recently, research has shown that selective (or partial) removal of carious tissue in primary teeth, prior to placement of a restoration, or indeed no caries removal at all (Hall Technique), can decrease postoperative complications. ${ }^{6}$

Two studies, conducted in specialist paediatric dental practice, have been recently published. A hospital-based RCT in Germany found lower failure rates after one year with the Hall Technique over conventional restorations or prevention alone treatment $\left(0 \%, 9 \%\right.$ and $8 \%$ respectively). ${ }^{7}$ Additionally, a retrospective case note analysis showed high success rates using preformed metal crowns; conventionally and with the Hall Technique (94\% and 97\% respectively). 8

Evidence from specialist practice does not seem to have translated into primary care, with the proportion of primary teeth with visible caries that are restored (the Care Index) remaining low (Scotland 13\%; England 14\%). ${ }^{9}, 10$ Several general dental practice based studies have questioned the role of restorations in primary teeth (Table 1). ${ }^{11,12}$ In both studies, significant proportions of children experienced pain and/or sepsis, ${ }^{13}$ however, the studies were limited in the inferences that could be drawn because of the relative weakness of retrospective reviews of case notes and additional study design flaws. ${ }^{14,15}$ Recent evidence supports the use of the Hall Technique in primary care, ${ }^{16}$ however, the practitioners involved were from a single geographical area, limiting generalisability of the findings. A survival analysis study of restorations provided for a large $(n=2408)$ cohort of $4-5$ year olds indicated that restorations can improve the likelihood of a primary tooth exfoliating 
without need for extraction. The need for extraction was dependent upon the age at which caries occurred, with early recording of caries more likely to lead to extraction. ${ }^{17}$

Dental caries remains the primary reason for children being admitted to hospital for treatment under general anaesthetic in the UK. ${ }^{18}$ In 2013/14, over 62,747 children and young people were admitted to hospitals in England, Scotland and Wales with a diagnosis of dental caries; the most common age group being 5-9 year olds (Table 2). This care has high direct costs for the NHS, with over £30 million spent on hospital-based tooth extractions for children aged 18 years and under for England alone in 2013-14 (NHS reference costs 2013/14). Indirect costs also accrue from this treatment (e.g. time off work, childcare, non-prescribed medications).

In response to the evidence that dental caries was not being managed optimally and carried significant costs, the UK National Institute for Health Research (NIHR) Health Technology Assessment (HTA) Programme issued a call in 2007 to commission a study to answer the research question: "What is the clinical and cost-effectiveness of fillings in primary teeth, compared to no treatment?" (Figure 1). As a result of that call, the FiCTION trial (registration no. ISRCTN77044005), a three-arm, parallel group, patient-level RCT, based in general dental practice and study, was funded; the published protocol can be found at http://www.biomedcentral.com/1472-6831/13/25. ${ }^{19}$ The three interventions being assessed include an intermediate arm and are detailed in Table 3. All children in the trial, irrespective of allocated treatment arm, receive the same level of preventive care, i.e. best practice prevention. ${ }^{18,19}$ The FiCTION collaboration comprises clinicians and researchers from nine dental institutions across the UK with external oversight from a Trial Steering Committee and Independent Data Monitoring Committee.

\section{Pilot Rehearsal Trial and Feasibility Study}

Before commencing the main FiCTION trial (Trial Registration: ISRCTN77044005), a feasibility study and pilot rehearsal trial were conducted. ${ }^{20}$ In the feasibility study, a postal questionnaire sent to a randomly selected group of dental practices $(n=273)$ in potential FiCTION trial areas gauged practitioners' levels of interest and readiness to participate in the study. Ninety seven practices responded and of these 70 (72\%) said they would be prepared to participate in the FiCTION trial.

The pilot rehearsal trial allowed the research processes (e.g. screening, recruitment, data collection) to be assessed prior to commencing the main trial and is discussed later. In parallel, a qualitative investigation of the views and opinions of both service providers (dentists and the practice team) and participants (children and their parents) on participating in FiCTION processes ${ }^{20}$ was undertaken. 
The findings of these studies were used to modify practice training, improve research processes and increase the required screening numbers for the main FiCTION trial. ${ }^{21}$

\section{The Main Study}

\section{Design}

The FiCTION trial commenced in 2012 (Figure 1). The recruitment phase is now complete and participant follow-up is underway. The primary outcome for the trial is the incidence of pain and/or sepsis for the three different caries management approaches carried out over a three-year period. Secondary clinical outcomes include; incidence of caries in primary and secondary teeth, quality of life, acceptability of treatment experiences to children and parents, and dentists' treatment preferences. ${ }^{19}$

The main economic objective of FiCTION is to determine the incremental cost per episode of pain and/or sepsis for the different treatment approaches. To allow a full understanding of cost-effectiveness and add value to the analysis, two different ways of measuring incremental costs will be compared; (i) time/material-based costs (cost at the practice level); and (ii) the current cost to the NHS for treating children with caries in primary teeth incorporating national funding arrangements.

Dental practices across five main regions of the UK (London, North-East England, Scotland, Wales, Yorkshire), with the later addition of Liverpool and Manchester have been recruited and trained for the study. Each centre has a Clinical Lead who is a Specialist in Paediatric Dentistry. Eligibility for FiCTION participation depended on practices caring for children under National Health Service contracts with participating practices inviting children to be screened for potential participation in FiCTION against eligibility criteria (Table 4) as part of their routine check-up.

\section{Progress to date}

The target sample size required for the FiCTION trial was initially calculated based on pain and/or sepsis rates recorded in the literature. ${ }^{11,12,16}$ Assuming three-year rates of $20 \%, 10 \%$ and $3 \%$ for the Prevention alone, Conventional with prevention and Biological with prevention arms respectively, and allowing for loss to follow up over the three years of $25 \%$, it was calculated that a total of 1461 child participants would provide $90 \%$ power for the comparisons of the differences in rates between the groups. Based on the FiCTION Pilot Trial, we predicted that 50 dental practices (80-100 dentists), screening a total of approximately 12,000 children and each recruiting to a target of 30 participants would be required to meet the overall recruitment target within 12 months (Figure 2). 
Practice recruitment and training for the main FiCTION trial commenced in summer 2012 (Figure 1). The first practices began to recruit participants in October 2012, although it took until spring 2013 to complete training and site visits for the first cohort (Phase 1; $n=44$ ) of practices. FiCTION-trained GDPs in each participating practice were responsible for child participant recruitment to the study.

By early 2013, it was evident that the child-participant recruitment rate was lower than initial projections (Figure 3). Dental practices, initially confident of recruiting sufficient participants, reported difficulties in finding enough children who met the inclusion criteria. The numbers of children judged to be clinically free of active caries appeared higher than predicted from the results of the Pilot Rehearsal Trial. Additionally, 17 practices (39\% of Phase 1 practices) became unable to continue with the trial for a variety of reasons.

In response to the shortfall in recruitment, additional dental practices were recruited through Phases 2-5 (Table 5). The impacts of the unanticipated training of new practice staff plus 28 additional practice set-up and associated monitoring visits placed pressure on trial financial, time and staff resources. To date, 72 recruiting practices (209 dentists; 228 team members) have been trained.

By the end of 2013 it had become apparent, with the recruitment rate dwindling, that achieving the target of 1461 participants was unlikely (Figure 3). To address this a contract variation was submitted to the HTA in August 2014 in which it was projected that, with a 12 month extension, the trial could recruit 1113 child participants by June 2015. Of these, the 996 randomised by June 2014 will have the originally proposed three-year follow-up while the remaining 117 participants will have a variable follow-up of between two and three years with follow-up complete by June 2017 . These measures would allow for $82 \%$ power to detect a difference between the groups and was accepted by the HTA. Additional practices were then recruited in Manchester and Liverpool to help reach the revised target (Table 5).

\section{What have we learnt so far}

There is a drive to improve efficiency within trials ${ }^{22}$ and although FiCTION is ongoing, valuable lessons have already been learnt; most notably through the conduct of the pilot rehearsal trial and feasibility study, summarised above ${ }^{20}$, and supplemented more recently by a mid-recruitment survey of dental practices to determine the main barriers and facilitators to participant recruitment. ${ }^{23}$

\section{From the Pilot Rehearsal Trial}

Conducted in three regions of the UK (Scotland, North-East England and Sheffield), the Pilot Rehearsal Trial involved 11 practices (20 dentists) and ran from January 2010 to October 2011 (Figure 1). Whilst uptake amongst eligible participants was high (80\%), by the end of this 18-month pilot, fewer 
than $50 \%$ of the expected number of patients had been recruited. This was valuable information which, along with the comments and suggestions of stakeholder groups (Table 6) helped inform main trial planning in a number of ways including a revision of the planned numbers of children to be screened.

On the basis of this feedback, changes made to the main trial included:

- $\quad$ paperwork refined to allow more efficient completion;

- FiCTION-branded merchandise was created for participants; Fluffy bugs, colouring-in pages, brushing timers, bookmarks;

- colouring-in competitions; and

- quarterly Newsletter for distribution to practices.

These modifications aimed to make participation more straight-forward for practices and dental teams and pro-actively engage participating children in the research ${ }^{24}$. The introduction of FiCTION merchandise was well received by the children as a gesture of thanks for their efforts in the study (Figure 4).

\section{From the Mid-recruitment questionnaire}

Having initially recruited strongly (Figure 3), the rate of participants joining FiCTION began to slow around May 2014. This is well recognised as a common pattern and many trials in different settings struggle to recruit to target. ${ }^{25-27}$ However, in order to understand and try to address the barriers to recruitment, a web-based questionnaire study ${ }^{23}$ was conducted to allow practitioners to comment on participant recruitment processes

An existing clinical trial survey tool was adapted to reflect the major differences in contextual settings of FiCTION (i.e. primary dental environment) ${ }^{28}$. This modified survey was distributed online ${ }^{29}$ and explored practitioners' and dental team members' views on their experiences of participating in the trial and allowed them to suggest improvements to facilitate participant recruitment.

Although some proposals involved aspects of the trial that were inflexible at this stage; for example; increasing eligibility criteria (age range), additional remuneration for practices, and simplifying the paperwork, other proposals were amenable to intervention, for example, increasing the number of site, acknowledgement of the effort of teams and participants and offering training to additional team members (Table 7).

\section{Ongoing changes}

Recruitment challenges in clinical trials are not limited to FiCTION or to dentistry $25-27,30$ and later recruitment difficulties were managed with a flexible approach iteratively. Practices joining later were asked to carry out a database search for patients of appropriate age to ensure an eligible child participant cohort. Practices were also encouraged to send the trial team a copy of their letterhead and lead dentist's CV prior to a full commitment to the 
trial which allowed their interest and compliance with trial-related processes to be gauged.

Review and refinement of the training process for FiCTION practices throughout the trial has enabled new practitioners and teams to be recruited and trained with minimal disruption to clinics. This has been particularly valuable when bringing new dentists into existing FiCTION practices.

In terms of communication with practices, we have responded to practitioners preferences for contact by the trial team. Initially, evening meetings were held for FiCTION practices but, as the trial has progressed, we have moved to lunchtime teleconferences in some areas. This has improved attendance and allowed more practitioners to share their thoughts on how trial processes could be further improved.

Feedback suggests that the changes actioned over the course of the study have positively contributed to reaching our revised target of 1113 participants. Given the work required to achieve this target, the FiCTION trial represents a rich source of information about the design and conduct of research trials in primary dental care.

\section{Conclusion}

The outcomes of the FiCTION trial will be known in early 2018. It is not possible, nor appropriate, to hypothesise at this time which treatment arm might be the most clinically- and cost-effective. One treatment arm may be superior for the primary outcome with a reduction in pain/infection incidence. However, should there be no clear difference, the secondary outcomes (costs, anxiety, provider preferences, quality of life, etc.) will help inform the overall trial conclusions and recommendations. For example, if children find it difficult to tolerate a clinically effective strategy, then its success in the practice setting could be reduced. The secondary outcomes will also inform decision-making about implementation of future clinical guidance into general practice.

This randomised controlled trial is being conducted on a scale not previously attempted in paediatric primary dental care. Research is not easy, particularly in the busy primary care setting and the FiCTION trial has been an ambitious project from the start. Whilst there have been difficulties, a successful participant recruitment phase has now moved into the equally important follow-up phase although the transition from recruitment to retention will no doubt hold new challenges. A flexible and pragmatic approach has been adopted throughout, whilst maintaining the rigorous principles required in research.

The progression of the trial has only been possible because of the goodwill and commitment of all the FiCTION dental practice teams across the UK, who continue to treat their FiCTION children. The findings will inform the clinical management of the primary teeth of children in UK through general dental practitioners, evidence-based recommendations, commissioning of services 
and policy and ultimately will positively impact upon the health and experiences of our young patients.

\section{Acknowledgements}

We would like to thank the rest of the FiCTION study team, dental teams, child participants and parents taking part. This project was funded by the National Institute for Health Research [HTA] (project number 07/44/03). The views and opinions expressed therein are those of the authors and do not necessarily reflect those of the [HTA], NIHR, NHS or the Department of Health.

\section{References}

1. Chadwick BL, Evans DJ. Restoration of class II cavities in primary molar teeth with conventional and resin modified glass ionomer cements: a systematic review of the literature. Eur Arch Paediatr Dent. 2007 Mar;8(1):14-21.

2. Roberts JF, Sherriff M. The fate and survival of amalgam and preformed crown molar restorations placed in a specialist paediatric dental practice. British Dental Journal. 1990 Oct 20;169(8):237-44.

3. Welbury RR, Shaw AJ, Murray JJ, Gordon PH, McCabe JF. Clinical evaluation of paired compomer and glass ionomer restorations in primary molars: final results after 42 months. British Dental Journal. 2000 Jul 22;189(2):93-7.

4. Welbury RR, Walls AW, Murray JJ, McCabe JF. The 5-year results of a clinical trial comparing a glass polyalkenoate (ionomer) cement restoration with an amalgam restoration. British Dental Journal. 1991 Mar 9;170(5):177-81.

5. Fayle SA, Welbury RR, Roberts JF. British Society of Paediatric Dentistry: a policy document on management of caries in the primary dentition. International Journal of Paediatric Dentistry. 2001;11(2):153-7.

6. Ricketts D, Lamont T, Innes NP, Kidd E, Clarkson JE. Operative caries management in adults and children. The Cochrane database of systematic reviews. 2013;3:CD003808.

7. Santamaria RM, Innes NP, Machiulskiene V, Evans DJ, Splieth CH. Caries management strategies for primary molars: 1-yr randomized control trial results. Journal of Dental Research. 2014 Nov;93(11):1062-9.

8. Ludwig KH, Fontana M, Vinson LA, Platt JA, Dean JA. The success of stainless steel crowns placed with the Hall technique. The Journal of the American Dental Association. 2015/04/02;145(12):1248-53.

9. Macpherson LMD, Ball G, Conway DI. National Dental Inspection Programme 2012. Report of the 2012 Detailed National Dental Inspection Programme of Primary 1 Children and the Basic Inspection of Primary 1 and Primary 7 Children. The Scottish Dental Epidemiology Coordinating Committee by ISD Scotland, Edinburgh. 2012.

10. Davies G, Neville J, Rooney E, Robinson M, Jones A, Perkins C. National Dental Epidemiology Programme for England: oral health survey of five-year-old children 2012. A report on the prevalence and severity of dental decay Public Health England, London. 2013. 
11. Levine RS, Pitts NB, Nugent ZJ. The fate of 1,587 unrestored carious deciduous teeth: a retrospective general dental practice based study from northern England. British Dental Journal. 2002 Jul 27;193(2):99-103.

12. Tickle M, Milsom K, King D, Kearney-Mitchell P, Blinkhorn A. The fate of the carious primary teeth of children who regularly attend the general dental service. British Dental Journal. 2002 Feb 23;192(4):219-23.

13. Finucane D. Rationale for restoration of carious primary teeth: a review. Eur Arch Paediatr Dent. 2012 Dec;13(6):281-92.

14. Duggal PMS. Research summary: Carious primary teeth: their fate in your hands. British dental journal. 2002;192(4):215-.

15. Evans D. Letters. British Dental Journal. 2002;192(12):668-71.

16. Innes NP, Evans DJ, Stirrups DR. Sealing caries in primary molars: randomized control trial, 5-year results. Journal of Dental Research. 2011 Dec;90(12):1405-10.

17. Stephenson J, Chadwick BL, Playle RA, Treasure ET. A competing risk survival analysis model to assess the efficacy of filling carious primary teeth. Caries Research. 2009;44(3):285-93.

18. Royal College of Surgeons England. The state of children's oral health in England (2015)

19. Innes NP, Clarkson JE, Speed C, Douglas GV, Maguire A. The FiCTION dental trial protocol - filling children's teeth: indicated or not? BMC Oral Health. 2013;13:25.

20. Marshman Z, Innes N, Deery C, Hall M, Speed C, Douglas G, et al. The management of dental caries in primary teeth - involving service providers and users in the design of a trial. Trials. 2012;13:143.

21. Douglas, G.V.A., on behalf of the FiCTION Trial Collaboration, Usefulness of the FiCTION Pilot Rehearsal Trial and Feasibility Study, IADR Seattle 2013, 20 March 2013.

22. Treweek S. Trial forge: a systematic approach tomaking trials more efficient. Trials 2013 14(Suppl 1):0121.

23. Keightley A, Clarkson J, Maguire A, Speed C, Innes N. Participant recruitment to FiCTION, a primary dental care trial-survey of facilitators and barriers. British Dental Journal. 2014;217(10):E22-E.

24. Gilchrist F, Rodd HD, Deery C, Marshman Z. Involving children in research, audit and service evaluation. British Dental Journal. 2013;214(11):577-82.

25. Campbell MK, Snowdon C, Francis D, Elbourne D, McDonald AM, Knight R, et al. Recruitment to randomised trials: strategies for trial enrollment and participation study. The STEPS study. Health Technol Assess. 2007 Nov;11(48):iii, ix-105.

26. McDonald AM, Knight RC, Campbell MK, Entwistle VA, Grant AM, Cook JA, et al. What influences recruitment to randomised controlled trials? A review of trials funded by two UK funding agencies. Trials. 2006; 7:9.

27. Sully BG, Julious SA, Nicholl J. A reinvestigation of recruitment to randomised, controlled, multicenter trials: a review of trials funded by two UK funding agencies. Trials. 2013;14:166.

28. Kaur G, Smyth RL, Williamson P. Developing a survey of barriers and facilitators to recruitment in randomized controlled trials. Trials.

2012;13(1):218. 
29. Bristol Online Surveys (BOS). Online information available at http://www.survey.bris.ac.uk/ (accessed May 2015).

30. Treweek S, Mitchell E, Pitkethly M, Cook J, Kjeldstrøm M, Johansen M, et al. Strategies to improve recruitment to randomised controlled trials. The Cochrane Library. 2010.

31. Child Dental General Anaesthetics in Wales. 2014. Public Health Wales. 32. Information Services Division Scotland. Dental statistics. (2014) http://www.isdscotland.org/Publications/index.asp (accessed May 2015). 33. Scottish Dental Clinical Effectiveness Programme (SDCEP): Prevention and management of dental caries in children. Dundee: SDCEP; 2010.

34. UK Department of Health and British Association for the Study of Community Dentistry (BASCD): Delivering better oral health. An evidence-based toolkit for prevention. 2nd edition. London: Department of Health; 2009. 35. Yengopal V, Harnekar SY, Patel N, Siegfried N. Dental fillings for the treatment of caries in the primary dentition. The Cochrane Library. 2009. 
Table 1 - Comparison of failure rates of conventional restorations and nonrestorative caries treatment in primary care-based studies

\begin{tabular}{|l|l|l|l|l|}
\hline Study & $\begin{array}{l}\text { Number } \\
\text { of } \\
\text { restored } \\
\text { teeth }\end{array}$ & $\begin{array}{l}\text { Number of } \\
\text { unrestored } \\
\text { teeth }\end{array}$ & $\begin{array}{l}\text { Failure rate } \\
\text { (\%) of } \\
\text { restored } \\
\text { teeth }\end{array}$ & $\begin{array}{l}\text { Failure rate } \\
(\%) \text { of } \\
\text { unrestored } \\
\text { teeth }\end{array}$ \\
\hline $\begin{array}{l}\text { Tickle M., et } \\
\text { al. (2002) }\end{array}$ & 2085 & 563 & $17 \%$ & $14 \%$ \\
\hline $\begin{array}{l}\text { Levine R.S., } \\
\text { et al. (2002) }\end{array}$ & 0 & 1587 & - & $16 \%$ \\
\hline $\begin{array}{l}\text { Innes } \\
\text { N.P.T., et al. } \\
(2011)\end{array}$ & 132 & 0 & $17 \%$ & - \\
\hline
\end{tabular}

Table 2 - Distribution of General Anaesthetics in the UK for dental caries for children and young people (under 18 ) by country in year $2013 / 14^{18,31,32}$

\begin{tabular}{|l|l|}
\hline Country & Number of procedures \\
\hline England & 46500 \\
\hline Scotland & 7343 \\
\hline Wales & 8904 \\
\hline Total & $\mathbf{6 2 7 4 7}$ \\
\hline
\end{tabular}

Table 3 - FiCTION Treatment Arms

\begin{tabular}{|l|l|l|}
\hline $\begin{array}{l}\text { Best Practice } \\
\text { Prevention Alone }\end{array}$ & $\begin{array}{l}\text { Biological with Best } \\
\text { Practice Prevention }\end{array}$ & $\begin{array}{l}\text { Conventional with Best } \\
\text { Practice Prevention }\end{array}$ \\
\hline $\begin{array}{l}\text { Dental caries is } \\
\text { managed with best } \\
\text { practice preventive } \\
\text { care } 33,34 \text { to arrest } \\
\text { carious lesion }\end{array}$ & $\begin{array}{l}\text { Local anaesthesia is not } \\
\text { required Dental caries is } \\
\text { either partially removed } \\
\text { progression, with } \\
\text { teeth left to exfoliate } \\
\text { naturally in due } \\
\text { sealed from the oral } \\
\text { course. }\end{array}$ & $\begin{array}{l}\text { Dental caries is } \\
\text { environmentely removed, } \\
\text { generally under local } \\
\text { adhesive restorative } \\
\text { anaterials or a preformed } \\
\text { tooth restored with a } \\
\text { crown. }\end{array}$ \\
\hline
\end{tabular}


Table 4 - Child Participant Eligibility Criteria

\begin{tabular}{|c|c|}
\hline Inclusion & Exclusion \\
\hline - Aged 3-7 years at enrolment & - Lack of accompanying adult \\
- Caries into dentine in $\geq 1$ & legally able to consent \\
primary molar teeth & - Pain due to caries \\
& - Sepsis \\
& $\begin{array}{l}\text { - Medical condition requiring } \\
\end{array}$ \\
& treatment in secondary care \\
& Involvement in competing \\
& study \\
& - Likely to leave the practice \\
& catchment area during study \\
\hline
\end{tabular}

Table 5 - Distribution of practices who have recruited at least one participant to FiCTION according to region and phase of site entry

\begin{tabular}{|c|c|c|c|c|c|c|c|c|}
\hline \multicolumn{2}{|c|}{ Region } & London & $\begin{array}{l}\text { North- } \\
\text { East } \\
\text { England }\end{array}$ & Scotland & Wales & Yorkshire & $\begin{array}{l}\text { Liverpool } \\
\text { and } \\
\text { Manchester }\end{array}$ & Total \\
\hline \multirow{5}{*}{ 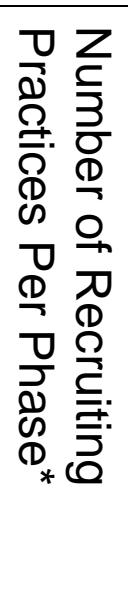 } & $\begin{array}{l}\text { Phase 1 } \\
\text { (Sep 12- } \\
\text { Jun 13) }\end{array}$ & 9 & 11 & 12 & 4 & 8 & - & 44 \\
\hline & $\begin{array}{l}\text { Phase } 2 \\
\text { (Jul 13- } \\
\text { Aug 13) }\end{array}$ & - & 2 & 2 & - & - & - & 4 \\
\hline & $\begin{array}{l}\text { Phase } 3 \\
\text { (Sep 13- } \\
\text { Nov 13 }\end{array}$ & - & 6 & 5 & - & 1 & - & 12 \\
\hline & $\begin{array}{l}\text { Phase 4 } \\
\text { (Feb 14- } \\
\text { Mar 14) }\end{array}$ & 2 & 1 & 5 & - & 2 & - & 10 \\
\hline & $\begin{array}{l}\text { Phase 5 } \\
\text { (Jan 15) }\end{array}$ & - & - & - & & - & 2 & 2 \\
\hline \multicolumn{2}{|c|}{ Overall } & 11 & 20 & 24 & 4 & 11 & 2 & 72 \\
\hline
\end{tabular}

${ }^{*}$ Month of site initiation visit 
Table 6 - Comments and suggestions of stakeholder groups

\begin{tabular}{|l|l|}
\hline Group & Comments and suggestions \\
\hline Participants & $\begin{array}{l}\text { - Stickers and colouring-in materials should be } \\
\text { available }\end{array}$ \\
& $\begin{array}{l}\text { - Some children didn't understand or remember the } \\
\text { trial }\end{array}$ \\
\hline Parents & $\begin{array}{l}\text { - Some felt they would like more information on the } \\
\text { trial }\end{array}$ \\
& $\begin{array}{l}\text { - Paperwork could be refined } \\
\text { - The appointments seemed to be longer }\end{array}$ \\
& $\begin{array}{l}\text { - Rewards for the children should be introduced } \\
\text { Dental teams }\end{array}$ \\
& $\begin{array}{l}\text { - } \text { - Lories was moresponse rates from invitation pack } \\
\text { - Unprepared for some treatment arms; conventional }\end{array}$ \\
& - arm, hall technique, radiographs \\
& Rigidity of study protocol was unfamiliar \\
\hline
\end{tabular}

Table 7 - Actions taken by trial team to support participant recruitment

\begin{tabular}{|c|c|}
\hline Suggestions & Action taken \\
\hline $\begin{array}{l}\text { Acknowledgment of } \\
\text { efforts of teams and } \\
\text { families of participants }\end{array}$ & $\begin{array}{l}\text { Practices successful in recruitment were } \\
\text { sent tea-break sets with FiCTION-branded } \\
\text { mugs as a small token of the trial team's } \\
\text { appreciation of their efforts. Participants } \\
\text { already received FiCTION merchandise as } \\
\text { part of their recall appointments }\end{array}$ \\
\hline $\begin{array}{l}\text { Increase recruitment of } \\
\text { practices }\end{array}$ & $\begin{array}{l}\text { - Additional sites were recruited from the } \\
\text { Manchester and Liverpool regions. } \\
\text { - Some additional practices had prior } \\
\text { hands-on experience of research projects }\end{array}$ \\
\hline $\begin{array}{l}\text { Training and delegation } \\
\text { to involve full practice } \\
\text { team }\end{array}$ & $\begin{array}{l}\text { The training syllabus for FiCTION was } \\
\text { modified to make the process simpler and } \\
\text { more effective to allow the entire practice } \\
\text { team to help with the process and } \\
\text { increase awareness of FiCTION }\end{array}$ \\
\hline $\begin{array}{l}\text { Positive support from } \\
\text { central FiCTION Team. }\end{array}$ & $\begin{array}{l}\text { - Additional intensive support was offered } \\
\text { mostly on site to new practices in the early } \\
\text { stages to assist in the transition from } \\
\text { training to recruitment. }\end{array}$ \\
\hline
\end{tabular}




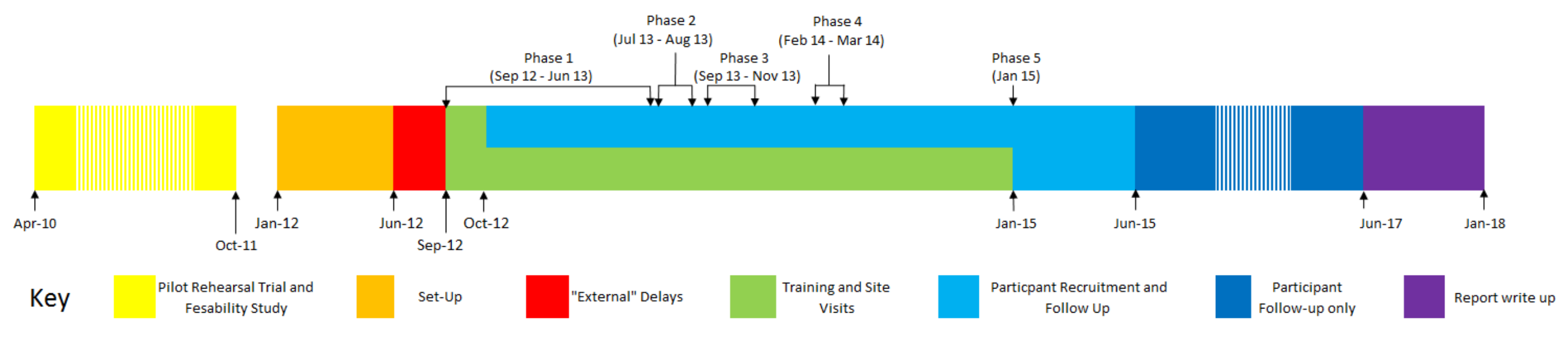

Figure 1 - FiCTION Timeline 
Figure 2 - FiCTION child participant journey flow chart as projected in original protocol

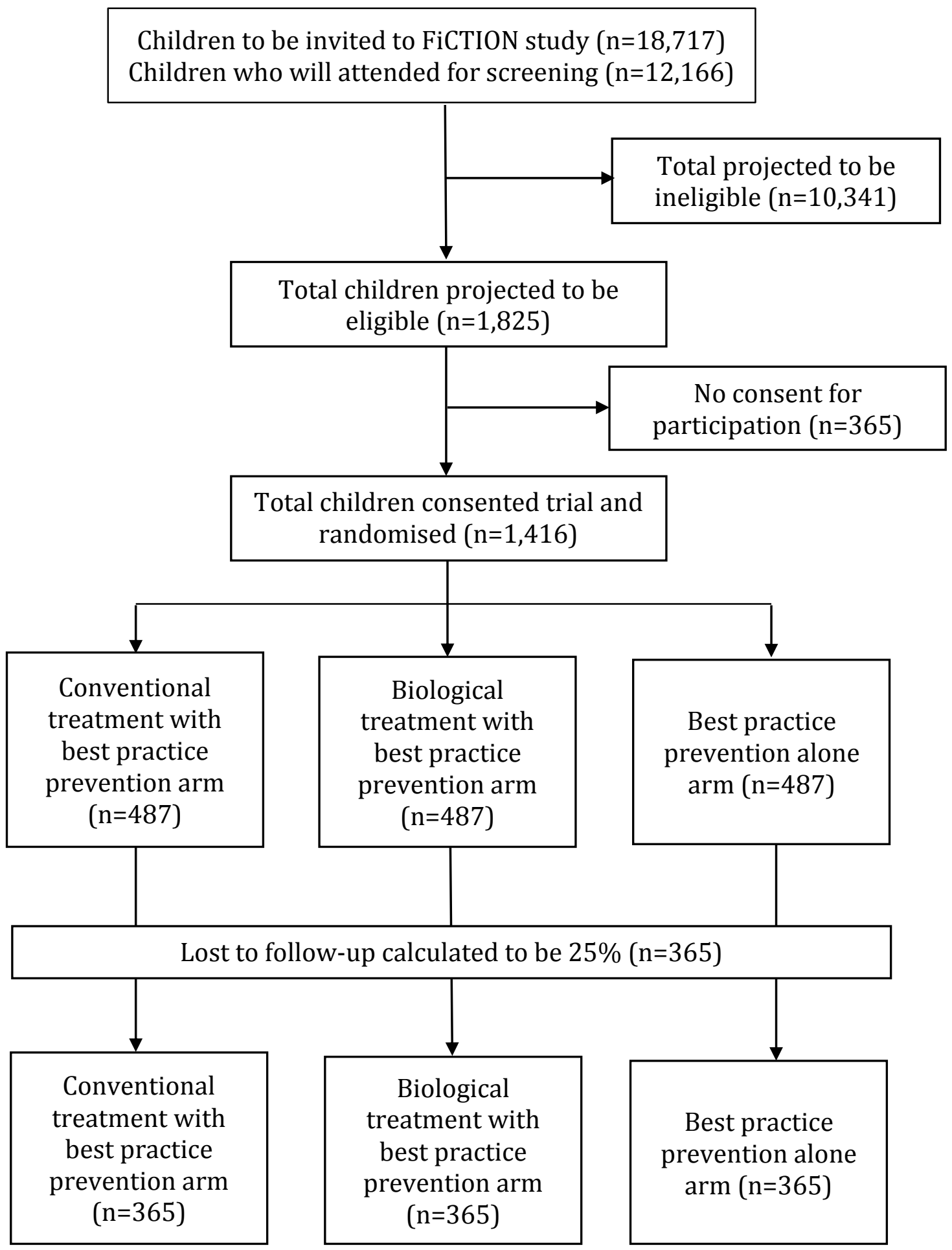




\section{FICTION RECRUITMENT}

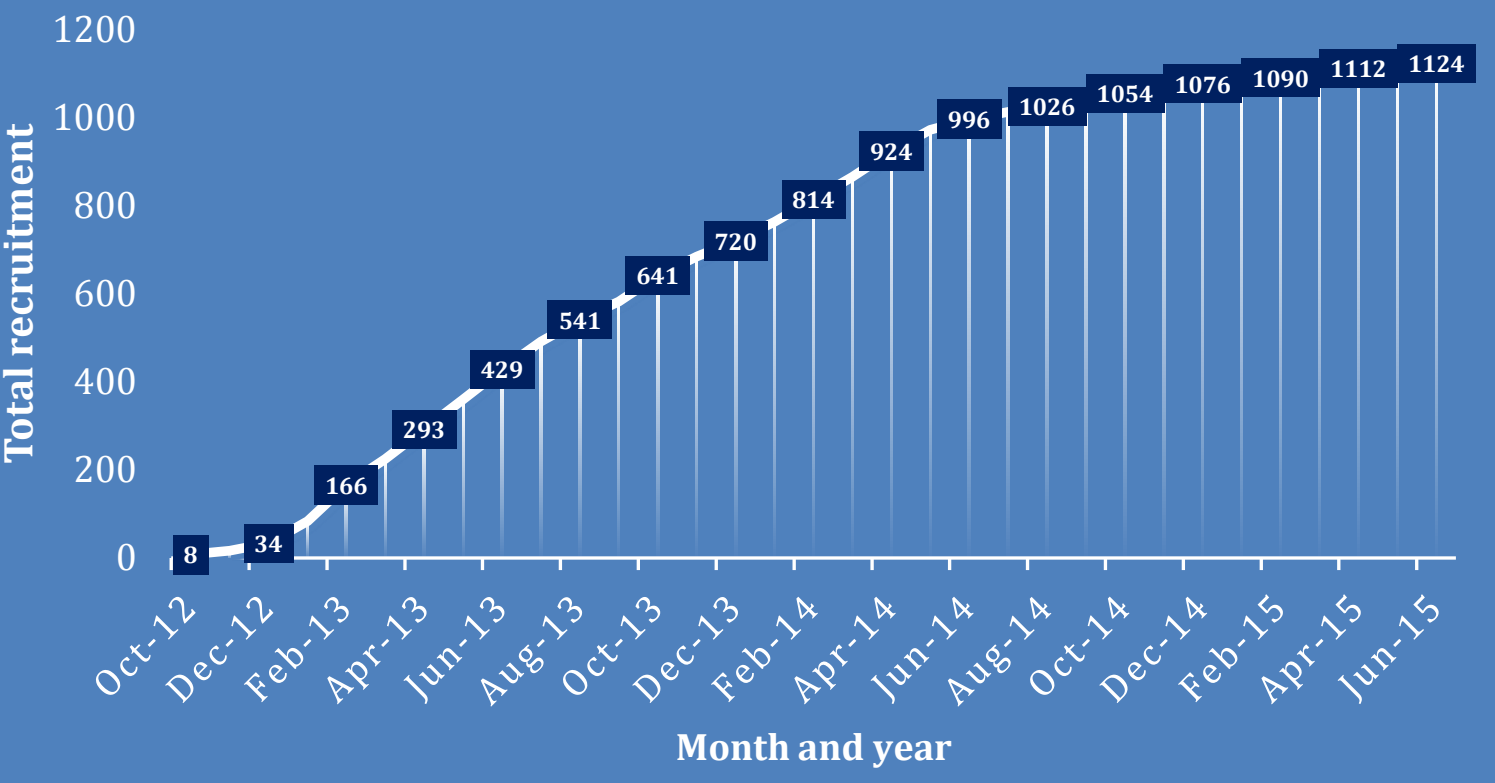

Figure 3 - FiCTION recruitment over time

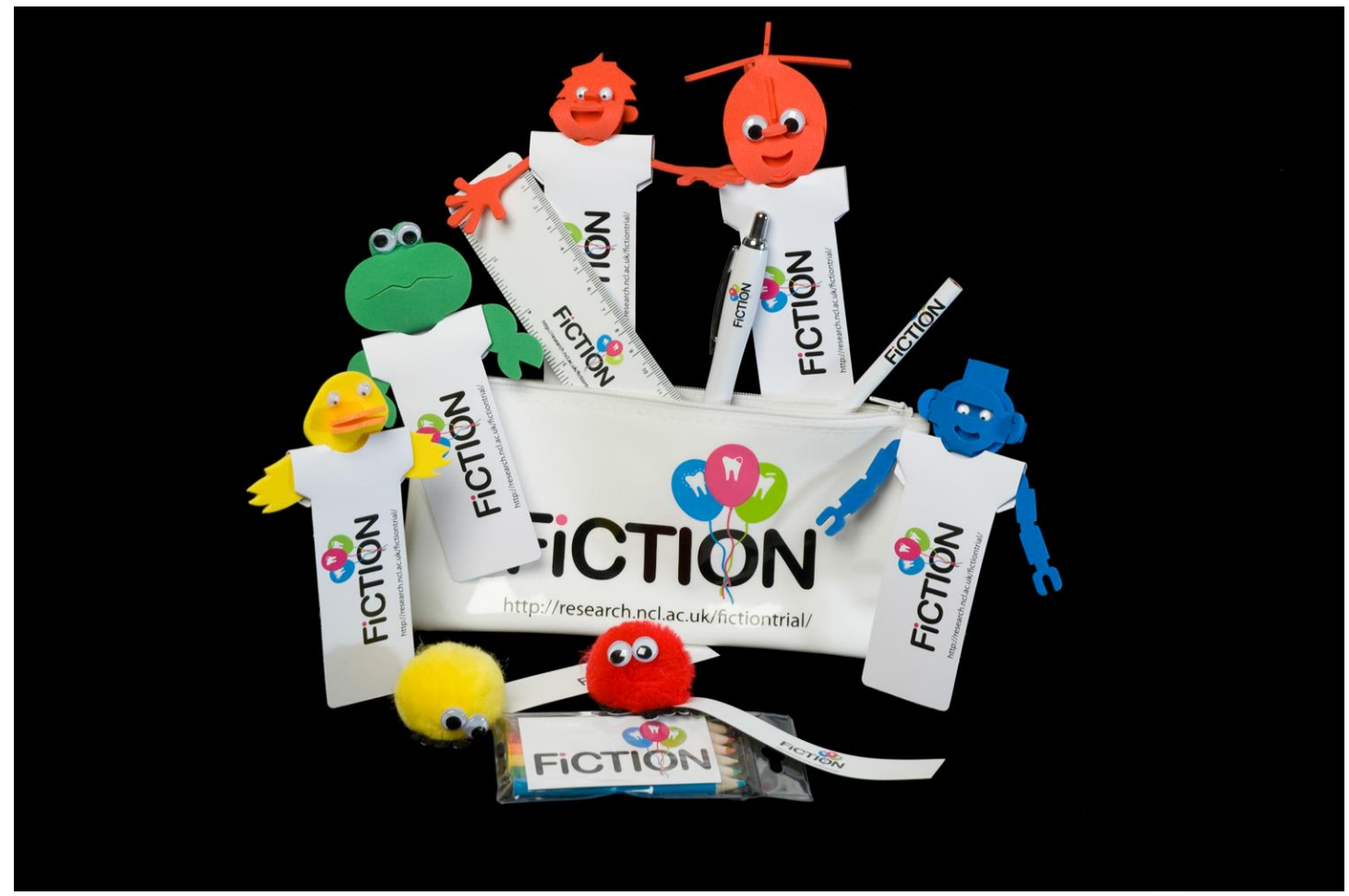

Figure 4 - FiCTION merchandise for participants 